\title{
An Updated Technical-Tactical Categorisation in Taekwondo: From General Tactical Objectives to Combat Situations
}

\author{
Merce Barrientos ${ }^{1, *}$, Miguel A. Saavedra-García ${ }^{1}$, Rafael Arriaza-Loureda ${ }^{2}$, Cristina Menescardi ${ }^{3} \mathbb{D}$ \\ and Juan J. Fernández-Romero ${ }^{1}$ \\ 1 Grupo de Investigación en Ciencias del Deporte (INCIDE), Universidade da Coruña, 15001 A Coruña, Spain; \\ miguel.saavedra@udc.es (M.A.S.-G.); juan.jose.fernandez@udc.es (J.J.F.-R.) \\ 2 Cátedra HM de Traumatología del Deporte, Instituto Médico Arriaza y Asociados, Universidade da Coruña, \\ 15001 A Coruña, Spain; rafael.arriaza@udc.es \\ 3 AFIPS Research Group, Universidad de Valencia, 46010 Valencia, Spain; cristina.menescardi@uv.es \\ * Correspondence: m.barrientos.varela@udc.es
}

check for updates

Citation: Barrientos, M.;

Saavedra-García, M.A.;

Arriaza-Loureda, R.; Menescardi, C.; Fernández-Romero, J.J. An Updated Technical-Tactical Categorisation in Taekwondo: From General Tactical Objectives to Combat Situations. Sustainability 2021, 13, 10493. https:/ / doi.org/10.3390/su131910493

Academic Editors: Antonio Hernández-Mendo, Coral Falco, Verónica Morales-Sánchez and Tomas Herrera-Valenzuela

Received: 8 May 2021

Accepted: 7 September 2021

Published: 22 September 2021

Publisher's Note: MDPI stays neutral with regard to jurisdictional claims in published maps and institutional affiliations.

Copyright: (c) 2021 by the authors. Licensee MDPI, Basel, Switzerland. This article is an open access article distributed under the terms and conditions of the Creative Commons Attribution (CC BY) license (https:// creativecommons.org/licenses/by/ $4.0 /)$.

\begin{abstract}
Taekwondo competition underwent enormous development with the recent introduction of electronic scoring devices and rule changes. Although the competitive model of taekwondo had been previously studied, most of the literature that analyses this model was previous to the introduction of electronic devices or not based on a prior system of categories. Not only are results of an up-to-date taxonomy essential to guarantee the sustainability of future research about taekwondo based on methodological observation, but they are also completely necessary. This article proposes and validates a new categorisation of taekwondoist technical-tactical actions in the competition after the modifications were introduced between Beijing 2008 and Tokyo 2021 qualification events. The association between environmental conditions, tactical objectives, and technical actions determines the defining parameters of the combat situations. To design the category system, a dual methodology was used: in the first stage, an in-depth review of the technical and scientific literature based on observation of combats was carried out. From that review, a synthesis document was produced, which subsequently was used as a basis for canvassing an up-to-date view of the question from expert advisers. The existing terminology and categories were rearranged and updated, establishing new parameters involved in the technical-tactical resources of contest situations. This updated categorisation was tested by using the generalisability theory, revealing excellent-to-perfect observers' agreement and reliable data. This new categorisation will allow designing precise and sustainable tools over time for methodological observation of taekwondo in future studies.
\end{abstract}

Keywords: combat sports; taekwondo; technical-tactical analysis; tactical objectives; technical actions; combat situation

\section{Introduction}

Taekwondo was included in the Olympics for the first time as a demonstration sport at the 1988 Seoul Games and became part of the official Olympic programme since Sydney 2000 in its sparring form [1]. This form categorises taekwondo among the group of sports termed adversarial [2] or combat sports [3].

From the neurophysiological point of view, the motor actions involved in taekwondo contests have a high degree of difficulty, and their use during the match, therefore, requires them to be highly automatised to ensure that these resources are immediately available without the need for considered formulation of a motor pattern to play a part during the action.

In its functional structure, taekwondo, according to a motor-praxeological classification [4], is a regularised, standardised, and institutionalised sport, without teammates, with an opponent, and without uncertainty in the environment (TOU). During the contest, the 
subject faces a single opponent (during the competition, there may be successive confrontations with different opponents) who may know the subject's strategies, though usually with incomplete information, which both contestants will try to use to frustrate their opponent's strategies [5]. Thus, in the context of the contest, constant motor counter communication occurs with the opponent-the only source of uncertainty—making the environment highly changeable [5]. These continuous changes define the motor skills involved in the contest as open, perceptual, or externally regulated. A high level of selective attention is therefore required to perceive and process relevant stimuli that will allow rapid decision making at every moment $[6,7]$.

Among the parameters that significantly affect any competition are the rules governing its conduct. It is noteworthy that the competition rules of taekwondo have undergone 40 changes since they were approved in 1973, and 12 of these occurred in the period between the Beijing 2008 and Rio 2016 Olympics [8]. In addition to the rules themselves, the aspects of competition that have been significantly modified include the protection and scoring system [5], which were specifically changed by substituting a subjective system for an objective one and in terms of the score assigned to each type of action valued, passing from 1 point for each one in 2008 to a range of 1 to 5 points depending on the height and trajectory in 2016.

These changes are important because to define a sport, we need to define its rules [9], and when these are modified, the competition model is altered, making it desirable to formulate a new updated theoretical framework. Thus, the aim of this study was twofold: (1) to propose an updated technical-tactical categorisation for observation analysis of elite taekwondo athletes, centred in combat situations and (2) to validate and test the reliability of an observational tool for analysing taekwondoists' technical-tactical actions of five bouts of four different elite tournaments (i.e., Olympic Games of Beijing 2008, Grand Prix Manchester 2014, Olympic Games of London 2012 and Rio de Janeiro 2016).

\section{Materials and Methods}

The design of the updated categorisation for the observational tool, validation, and calculation of reliability were carried out in different stages, in line with the literature $[6,9,10]$, as follows: (a) the literature review was carried out, the first draft of the observational instrument was designed, and expert revision of the instrument was performed; (b) Once the revised version was stated, authors proceeded with the calculation of observers' and tool reliability by using the generalisability theory $[7,11,12]$.

\subsection{The Design of Technical-Tactical Categorisation}

In order to produce an objective, systematic, and up-to-date categorisation of taekwondo contest actions, we conducted a comparative review of the didactic literature and the theoretical and scientific proposals that have established categories for observing contests and produced a proposed synthesis based on the analysis and on contributions from the authors themselves. This proposal was subsequently reviewed by three experts (J.B.D., A.B.A.S., and J.A.T.T., Table 1) with proven experience in international taekwondo competitions.

Table 1. Criteria that had to be met by the experts selected as advisers.

\begin{tabular}{cc}
\hline & Established Criteria for the Election of Expert Advisors: \\
\hline 1 & International taekwondo trainers and coaches with World Taekwondo Federation \\
accreditation licence.
\end{tabular}

In the first phase, 35 different documents, articles, and books on the subject were reviewed. The results were discussed by the authors in order to establish a first draft of 
terms. Subsequently, two consensus meetings were held between the authors and the advisers.

As indicated in Table 2, at the first meeting, the initial information was discussed, and the various expert opinions were taken into consideration. On the basis of these contributions, a first consensus document was produced. The authors then carried out a second expanded review of the theoretical and scientific literature, based on searches for bibliographical references in the main search engines. The relevant information was incorporated into a second draft. The new document was submitted to the experts and discussed at a second consensus meeting. At this meeting, consensus agreements were reached, and a second document was drawn up. This was sent once again to all the participants, giving them a new deadline to contribute further issues or opinions before drafting a final document containing all the contributions. The final document was unanimously approved by all those participating in the project.

Table 2. Phases in the production of the consensus final document.

\begin{tabular}{|c|c|}
\hline & Phases in the Production of the Consensus Document: \\
\hline 1 & Theoretical-scientific and technical bibliography review. \\
\hline 2 & Main tactical objectives determination. \\
\hline 3 & $\begin{array}{l}\text { Definition of the roles which contestants can adopt according to each tactical objective } \\
\text { and the parameter 'initiative'. }\end{array}$ \\
\hline 4 & $\begin{array}{c}\text { Construction of the 'technical-tactical resource' concept by the association of the } \\
\text { objectives, roles, and technical elements. }\end{array}$ \\
\hline 5 & $\begin{array}{l}\text { Establishment of the parameters that affect the election of technical-tactical resources: the } \\
\text { environmental factors. }\end{array}$ \\
\hline 6 & $\begin{array}{c}\text { Synthesis of the concept of 'contest situation' and determination of the factors that } \\
\text { condition it. }\end{array}$ \\
\hline
\end{tabular}

\subsection{Technical-Tactical Categorisation Validation}

This study was carried out using the observational methodology, consisting of active, non-participatory observation. The observational tool was developed using an N/S/M observational design: nomothetic ( 8 athletes), with follow-up between sessions ( 5 bouts were recorded) and intrasession monitoring (continuous recording of specific movements), and multidimensional (since the observational tool is a mixed tool based on a category system and field format; see Table 3).

To validate and test the reliability of an observational tool, five bouts were rated by three observers. To determine the observer's agreement, the intraclass correlation coefficient (ICC), Cohen's kappa, and Kendall's Tau-b indices were computed. Additionally, the reliability between the observations made (interobserver's agreement) was tested by a generalisability analysis, which was also used to test the validity and accuracy of the newly updated categorisation. The generalisability analysis SAGT was used [12] with multifaceted designs that included three facets: observers [O], categories [C], and bouts [B] To use generalisability theory effectively, one needs to determine the variance components which generate errors in design and the relative weights of these components. In this sense, the $\mathrm{CB} / \mathrm{O}$ model evaluates interobserver agreement in the categories observed in the bouts selected, determining whether the observations made are reliable (its results are close to one). The $\mathrm{O} / \mathrm{C}$ model tests the goodness of fit of the categories, that is, whether they are exhaustive and mutually exclusive (E/ME). It is required that this model tends towards zero, indicating well-fitting, heterogeneous categories. Model C/B determines whether the observed behaviour in the analysed combat can be extrapolated to the total population. When this model tends towards one, it indicates that the sample used is sufficient to generalise the data to the population. D study was performed when $\mathrm{G}$ coefficients $<0.80$. 
Table 3. Consensus record sheet about parameters affecting the contest situations during a taekwondo match.

\begin{tabular}{|c|c|c|}
\hline Criteria & Category & Data Measurement \\
\hline \multirow{6}{*}{ Context } & Event: & Name \\
\hline & Contest number & $\mathrm{N}^{\mathrm{o}}$ \\
\hline & Gender & Male/female \\
\hline & Weight & $-58 /-68 /-80 /+80 /-49 /-57 /-67 /+67$ \\
\hline & Phase & 1ST/2ND/3RD/4TH/5TH/semifinal/final/repechage $\mathrm{n}$ \\
\hline & Pss colour & Blue/red \\
\hline \multirow{4}{*}{ Competitor } & Contestant/competitor & Blue/red (or name) \\
\hline & Weight & $\mathrm{Kg}$ \\
\hline & Heigh & $(\mathrm{cm})$ \\
\hline & Legs length/leg reach & $(\mathrm{cm})$ \\
\hline \multirow{9}{*}{$\begin{array}{l}\text { Contest situation } \\
\text { characteristics }\end{array}$} & Order of the contest situation & Number \\
\hline & Start & (s from the beginning) \\
\hline & End & (s from the beginning) \\
\hline & Duration & (ms) \\
\hline & Remaining time & (s to the end) \\
\hline & $\begin{array}{c}\text { Decisive moment (irreversible } \\
\text { advantage) }\end{array}$ & Yes/no \\
\hline & Space (on the mat) & Centre $(4 \times 4) /$ surrounding/boundary line \\
\hline & Interaction distance & Infra-critical/crítical/supra-critical/clinch \\
\hline & Scoring interaction result & $+\mathrm{n} / 0 /-\mathrm{n}$ \\
\hline \multirow{7}{*}{$\begin{array}{l}\text { Technical-tactical resource } \\
\text { characteristics }\end{array}$} & Initiative & Own/opponent/stand by \\
\hline & Role & Attacker/counterattacker/defender/no explicit \\
\hline & Technical-tactical action & $\begin{array}{c}\text { Attack/neutralisation/anticipation/simultaneous/falling/ } \\
\text { confront/dodge/feint/pressure }\end{array}$ \\
\hline & Action subtype & $\begin{array}{l}\text { Direct/indirect/cut/clash/block/displacement/gestema/ } \\
\text { positional change/advance/closing spaces }\end{array}$ \\
\hline & Complexity & Simple/combined/adjusted \\
\hline & Technical-tactical resource & Specific denomination \\
\hline & Concluding event & $\begin{array}{l}\text { Score/point-gap/pause/takedown/time } \\
\text { limit/exit/clinch/incident or accident }\end{array}$ \\
\hline \multirow{5}{*}{ Effectiveness } & Effectiveness/outcome & Positive/negative (respect to the tactical objective) \\
\hline & Misadjustments (if negative) & Spatial/temporal/technical/decisional/random \\
\hline & Relative effectiveness & Scoring difference after the situation ends \\
\hline & Scoreboard & $X-Y$ \\
\hline & External influences & Coach/judges/referee/instant video-replay claim \\
\hline
\end{tabular}

\section{Results}

\subsection{The Design of Technical-Tactical Categorisation}

According to the research consensus, the first major division in the tactical scheme occurs between two possible objectives: deciding either to seek a scoring advantage or to try to prevent the opponent from gaining an advantage [7]. The first objective results in offensive tactical actions, and the second leads to defensive tactics. The two objectives are mutually exclusive, although they may be pursued consecutively or alternately for very brief periods of time. As can be seen in Figure 1, once the objective has been established, the contestants adopt a role appropriate to it. The offensive tactical objective is attributed to the roles of attacker and counterattacker, and the defensive objective, to the role of defender. Additionally, there are transitions between the two previous tactical categories which correspond to the role of the athlete 'on standby' [7]. 


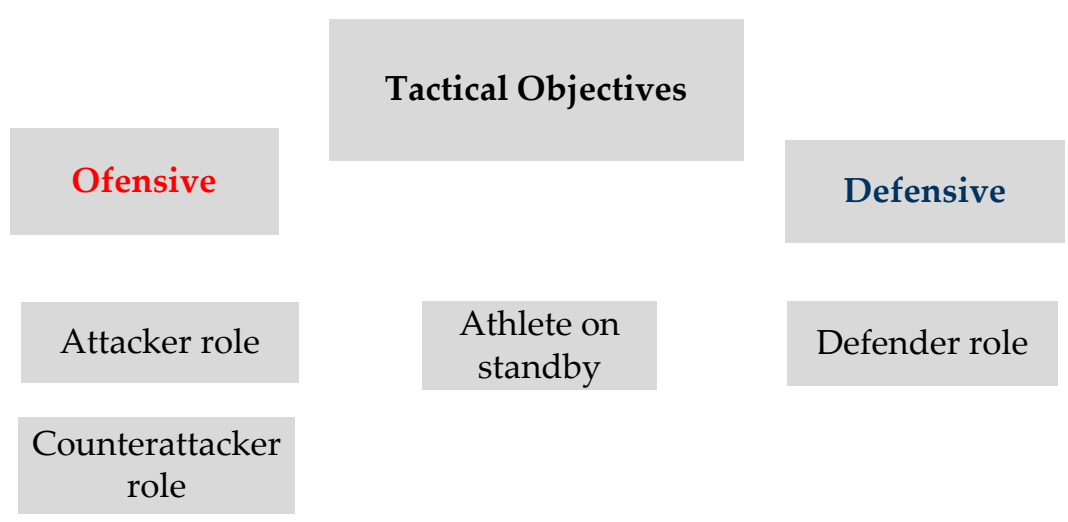

Figure 1. Categorisation of tactical roles according to primary tactical objectives.

As representing in the Figure 2, starting from the choice of objective and the role associated with it, the next major division is the initiative [7]. In every action analysed, we establish which of the two competitors has the initiative, in order to identify the role of attacker, as distinct from the other two possible roles, counterattacker and defender, both in response to the opponent's initiative. The role of the athlete on standby is also observed; it is established when no explicit initiative can be seen-that it, when one cannot objectively identify which contestant has the initiative-and its objective may be defensive (preventing an advantage to the opponent by evading the exchange of actions) or offensive (causing the opponent to be penalised for inaction or causing them to take the initiative in order to counterattack).

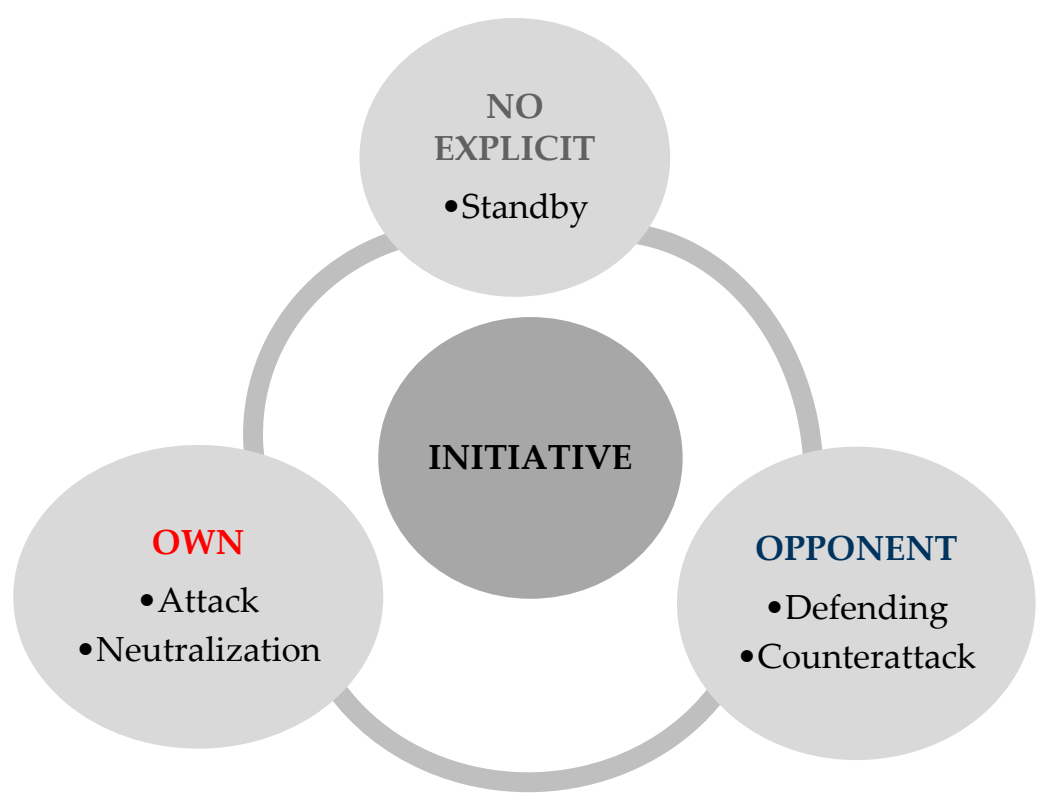

Figure 2. Initiative and tactical situations it defines.

Once the tactical objectives, initiative, roles, and tactical situations have been established, it is necessary to take account of the spatial, temporal, and contextual or environmental parameters, which will determine the choice of technical-tactical resources [7].

With regard to the spatial parameters, the distance separating the two contestants at each moment is critical [13] which enables us to distinguish four situations listed in Table 4.

As for the time factor, a taekwondo contest has a duration of three rounds of two minutes each with a one-minute rest period between rounds [8]. In the event of a tie at the end of the third round, a fourth 'sudden-death' round of one minute is added, using the 'golden points' system [8]. This temporal distribution determines the functional structure 
of the contest; however, beyond this stable structure, there are factors that affect the time available, that is, the time that remains in the contest to pursue a change of score or to keep it unchanged, or time relative to the opponent's actions-the existence and magnitude of a delay or lag between actions make it easier to determine whether the actions observed are related to each other or independent-enabling us to differentiate what have been termed 'combat times' which categorise attack and counterattack actions and divide them into three categories [12]: The reviewed studies have defined time-related subtypes of counterattack, such as anticipatory, or 'first phase', simultaneous, or 'second phase', and subsequent, or 'third phase', also known as 'descending' or 'falling' [9].

Table 4. Different types of distance observed during taekwondo contests.

\begin{tabular}{cc}
\hline Distance & Definition \\
\hline Critical & $\begin{array}{c}\text { The contestants are within reach of a single strike of the opponent. } \\
\text { Contestants cannot be reached by performing a single kick action. The } \\
\text { combination of several kicks or the association with displacements } \\
\text { is required. }\end{array}$ \\
$\begin{array}{c}\text { Contestants are too close to be kicked by a single or combined } \\
\text { kicking action. }\end{array}$ \\
Melee or clinch & The space between the two contestants, who are in contact, disappears. \\
\hline
\end{tabular}

An attack is an offensive action arising from one's own initiative that seeks to modify the result in one's favour. Within the attacker role, there is a subdivision: on the one hand, attack, a pure action (arising from the initiative-time-space parameters) and on the other, 'neutralisation' (anulación), an attack subtype that occurs after considered preparation against an opponent who is selecting a counterattacking response [7,12]. The attacker senses, perceives, or knows the counterattack that is being prepared and acts to neutralise it, using this information in their favour. Neutralisation is a specialised form of attack based on knowledge of the opponent and of their recurrent or probable choice of resources in counterattack $[7,12]$. The differences between the concepts of attack and neutralization are shown in Figure 3.

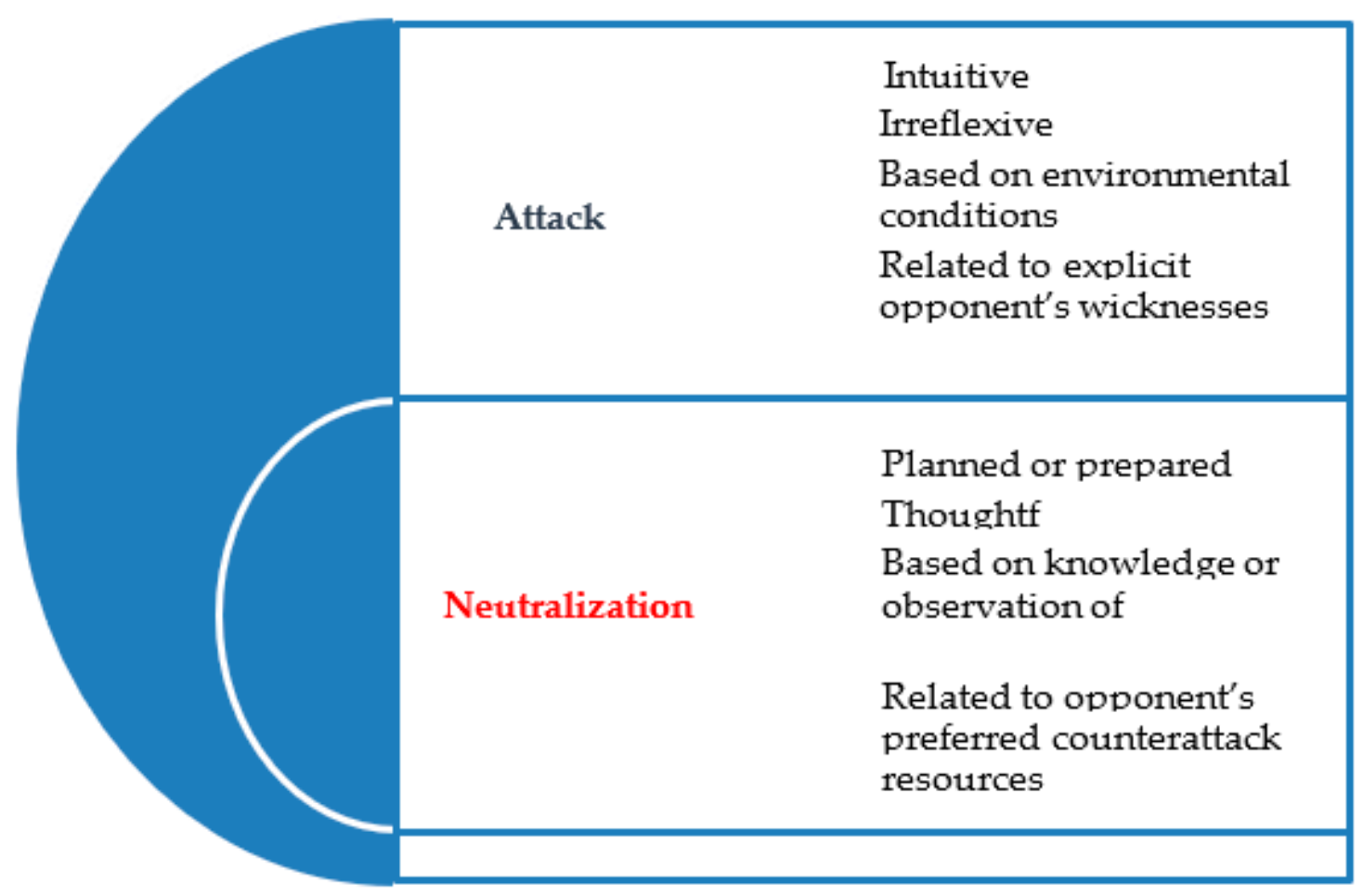

Figure 3. Attack and the 'neutralisation' subtype parameters. 
The technical-tactical resources, which are at the fourth level of tactical analysis (Figure 4), when used in an attack can be simple (isolated strikes), combined (strikes associated with movements, changes of stance, other strikes, etc.), or adjusted (kicks that begin as part of one technical action whose final or impact phase belongs to a different one) [5]. The choice of one resource rather than another is determined by contextual parameters and weaknesses of the opponent of various kinds (attentional, psychological, fatigue, positional balance, etc.) [12].

\section{Attacker Role}
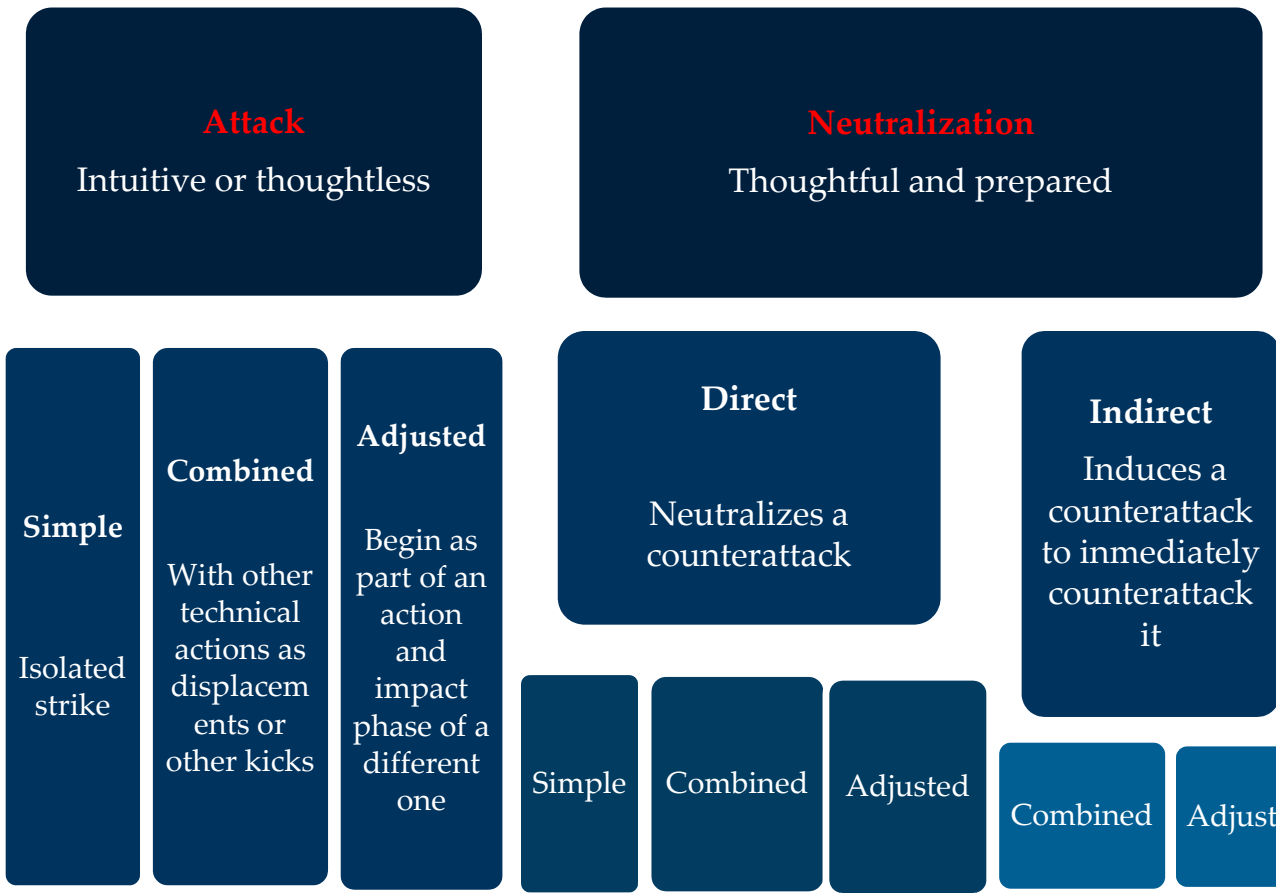

zes a

counterattack

Indirect

Induces a

counterattack

to inmediately

counterattack

it

Figure 4. Categorisation of technical-tactical resources in attack and neutralisation.

Neutralisation is direct when the attack neutralises a counterattack (preventing the opponent from performing it or limiting its effectiveness) and indirect-easier to observewhen the opponent is induced, by a feint, a movement, a change of stance, or a strike, to counterattack and put themselves at risk of receiving, in turn, a response to their action, during the most vulnerable phase of their counterattack. This is what is colloquially known in the jargon of other sports as a 'counter-counterattack' [5].

At some points in the contest, a dual initiative may occur, that is, two simultaneous attacks, without either action being a response to the opponent's initiative. Temporal or lag analysis helps to differentiate this situation from those in which there is an attackcounterattack pattern. Actions with an offensive objective in which the other contestant has the initiative are counterattacks. They depend on and adapt to the opponent's actions at the moment when they are executed [9], and this enables us, as shown in Table 5, to distinguish anticipatory or 'first-phase' actions, simultaneous or 'second-phase' actions, and subsequent or 'third-phase' actions, also known as 'descending' or 'falling' [9]. These three counterattack subtypes or phases occur at three vulnerable moments in the attacking action. 
Table 5. Subtypes of counterattack and execution times.

\begin{tabular}{|c|c|}
\hline Counterattack Subtype & Execution Moment \\
\hline Anticipatory actions & $\begin{array}{c}\text { When the opponent is initiating action and therefore } \\
\text { entering the critical distance. }\end{array}$ \\
\hline Simultaneous actions & $\begin{array}{c}\text { When the action is in progress, and the performer is in a } \\
\text { situation of inertia that prevents them from rectifying } \\
\text { their action. }\end{array}$ \\
\hline Falling or subsequent actions & $\begin{array}{l}\text { When the opponent, after the moment of impact (which } \\
\text { can be missed) is lowering their kicking leg, still in a } \\
\text { situation of instability, as they are on a single support. }\end{array}$ \\
\hline
\end{tabular}

The categorisation of counterattacks is affected by the time of execution relative to the attack and by spatial parameters such as the distance between the two contestants and the trajectory of the counterattacking techniques: as Figure 5 illustrates, anticipatory and simultaneous counterattacks occur within the critical distance or on the verge of it, whereas subsequent counterattacks, also named as posterior counterattacks [7], usually include a dodge, which increases the distance between the contestants until it is supra-critical, and which can also include a change of stance or relative position vis à vis the opponent. Simultaneous counterattacks, on the other hand, are executed using a trajectory, height, or impact zone contrary to that of the attack, with the object of avoiding (unproductive and frequently damaging) collisions and increasing the effectiveness of the counterattack [7].

\section{Counterattacker role}

Offensive response to the opponent's initiative
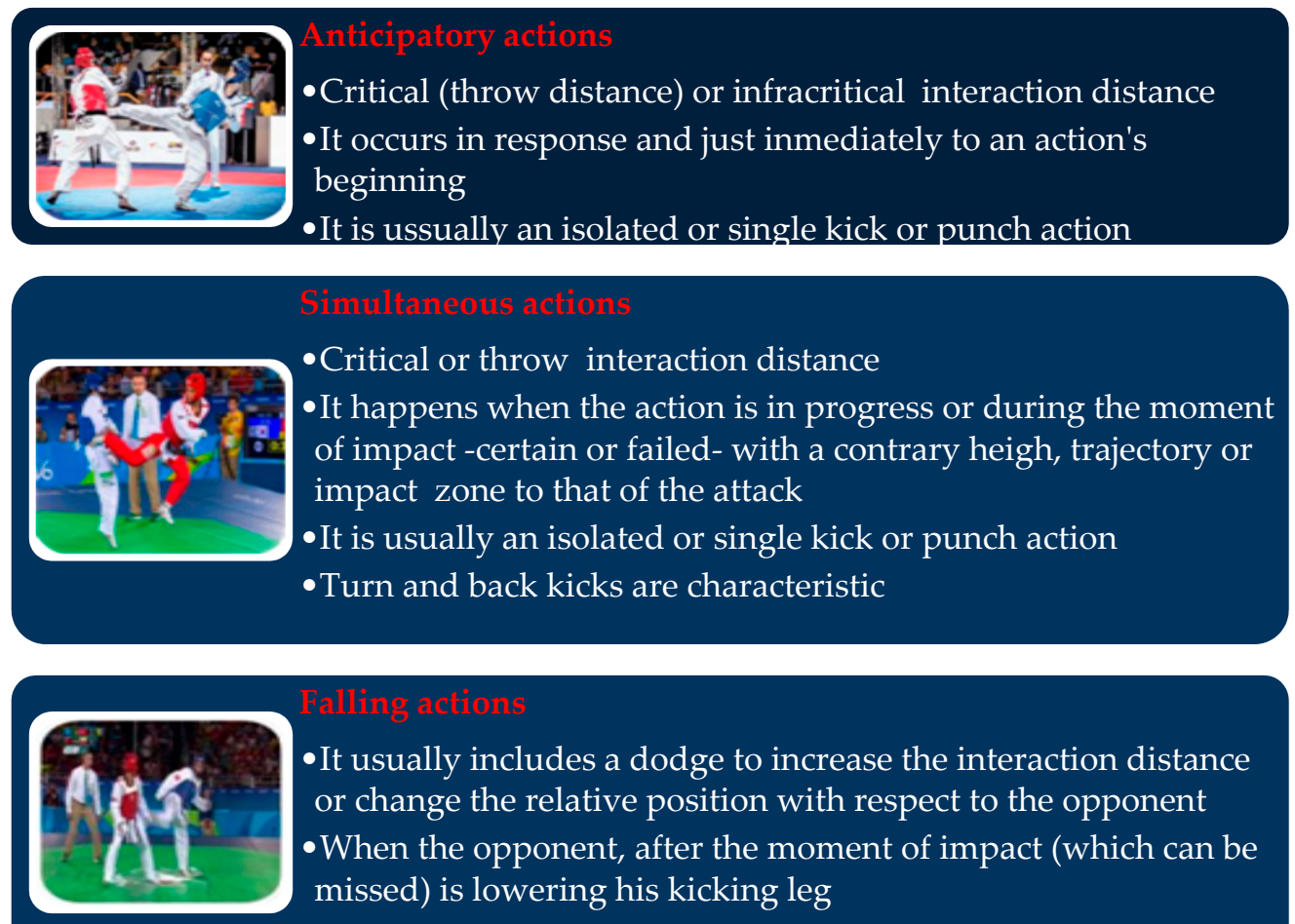

- It usually includes a dodge to increase the interaction distance or change the relative position with respect to the opponent

-When the opponent, after the moment of impact (which can be missed) is lowering his kicking leg

Figure 5. Technical-tactical resources in counterattack.

Defensive actions are those that seek only to prevent the opponent from gaining an advantage or to maintain the state of the contest unchanged [12]. When athletes take on the role of defender they submit to the opponent's initiative and merely try to invalidate 
the latter's actions or diminish their effectiveness. They resort to this role when they have a very favourable score, or when the temporal and spatial situation is unfavourable, and they cannot effectively execute a counterattack. This option also aims to minimise the risks or create doubts in the attacker by systematically rendering their technical-tactical resources ineffective, causing a debilitating psychological effect.

The introduction of objective scoring systems has given rise to blocks, defensive actions consisting of interposing a segment of the upper body (as the rules demand) with the object of preventing the attacker's strike from making contact with the sensors of the scoring devices, thereby avoiding adding points to the score [14]. Blocks are also used during offensive actions, but their object is still to reduce the effectiveness of a potential counterattack, in other words, to defend oneself [7].

As Figure 6 summarizes, other defensive resources used to neutralise or reduce the effectiveness of an attack are variations in the distance-reducing it from critical to infracritical or to a clinch is known as cutting distance and increasing it to supra-critical is dodging. A defensive resource introduced recently is the clash, also named as leg crash [15] or interposition of a lower limb in the trajectory of an attack to modify it or reduce the force of the impact which also makes the attacker lose their balance.

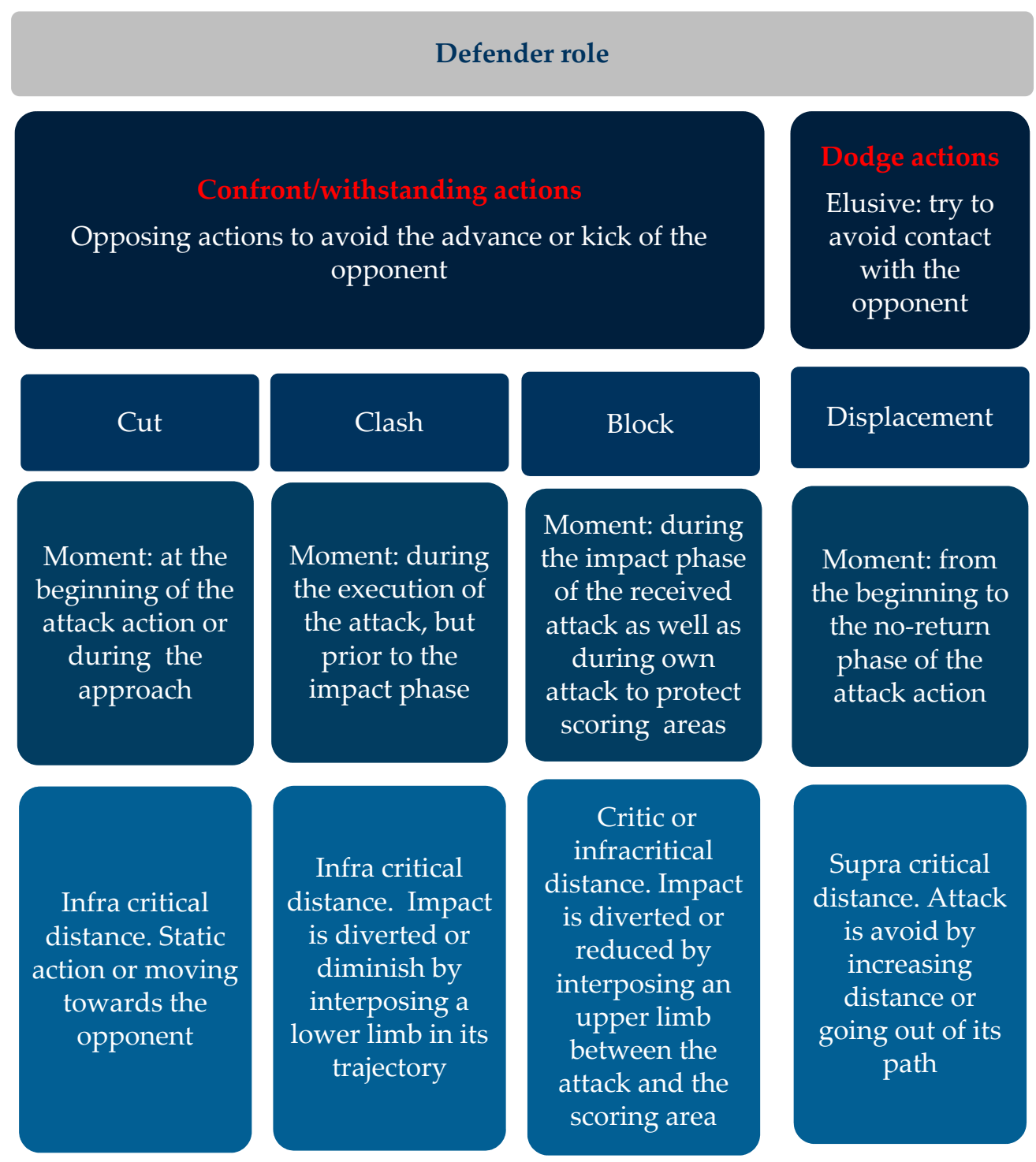

Figure 6. Tactical actions in defence. 
In the transitions between offensive and defensive actions, the role of the athlete on standby is found [5]. This non-fighting phase is confined to times when no action that fits into one of the foregoing categories is occurring [9], but it does not correspond to a neutral or resting position; it does not lack tactical purpose, as explained in Figure 7, and is frequently an interval in which the tension between the contestants reaches peak levels, and the actions performed also seek to determine the initiative or the contextual conditions of the contest.

\section{Role of Athlete on standby}

There is no explicit initiative from either of the two contestants
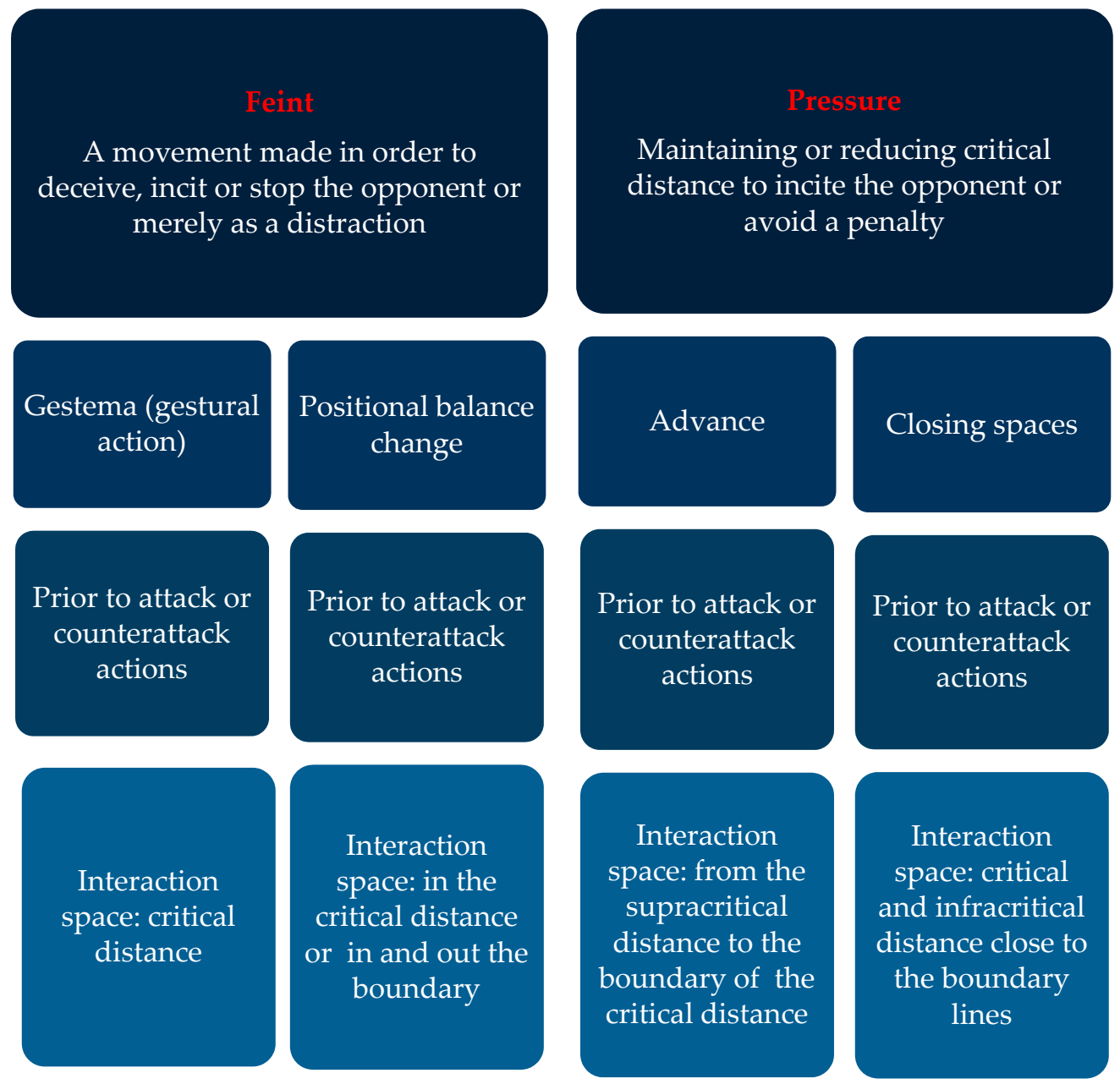

Figure 7. Categorisation of tactical actions of the athlete on standby.

During the course of a contest, the two subjects compete with the intention of winning, and this obliges them to make decisions every so often to preserve or modify the conditions of the contest. Objectives are chosen, the initiative is taken and technical-tactical resources are selected at various points during a contest according to determinants of contextual and other kinds. By isolating each moment at which these choices are made, we discover the existence of a unit which invests the choice of technical-tactical resources with meaning: the objective of each contestant is to turn the relationship of confrontation to their advantage, 
momentarily or permanently, and they have the chance to achieve this advantage in each combat situation by selecting actions to solve a problem or exploit an opportunity.

A combat situation starts from a pause (initiative on standby), which ends when one of the two contestants initiates the action. The other concludes with a result (a scoring interaction, positive or not) or triggers, in turn, a defensive response (block, cut, or dodge) or an offensive response (attack or counterattack). The situation culminates in a concluding event: a new pause, a knockdown, an interruption, either by the referee or of a temporal (time limit) or spatial nature (clinch or crossing the boundary line), or even an incident or accident [16].

Combat situations may follow on from each other immediately or after intervals of non-fighting pause whose duration is limited by the rules (five seconds) [8], or after a technical intervention by the referee (stopping the contest, for example), and they have an inherent meaning-influenced by the objectives, roles, and choice of technical-tactical resources-that is important for the result of the contest, which becomes a sequence of problems and opportunities. Finding solutions to fit the parameters that determine each situation and accumulating a larger number of successful actions than one's opponent are keys to a successful outcome: the result of a contest will be the summation of the results of each of the combat situations that occur successively during that contest.

An analysis of each combat situation confirms the effectiveness of the technical and tactical resources selected for the chosen tactical objectives, initiatives, and roles, depending on the contextual conditions of the contest. These are scoreline, space, and time [10], as well as the influence of agents such as coaches (who give instructions and request video replays) and judges or referees (who interrupt the contest, apply penalties, award points for punches, and request video replays). The effectiveness of a resource will also vary according to the sensitivity of the electronic devices [14]. Finally, physical parameters such as differences in body type, specifically in height and leg reach, will influence the choice of technical-tactical resources, since the ability to reach the helmet or face will affect their relative effectiveness [14]: the latter is not simply a matter of achieving a scoring interaction, since effective actions can obtain from 1 to 5 points depending on the area hit and the type of strike [8].

When analysing each combat situation, it will be essential to record the occurrence of all the elements mentioned and the outcome, as well as other data such as non-fighting times, the number of contest situations in each round, contest and phase of the competition, the contestant's number of successful resolutions of situations in attack, counterattack, and defence, and the decisive moments in the contest (the moment at which a difference starts to emerge in the scoreline, and the moment at which the advantageous position of a contestant becomes irreversible). Regarding the effectiveness or ineffectiveness of the resources used in each situation, we will analyse which parameters it is attributable to, whether spatial, temporal, technical (incorrect technical execution), decisional (making the wrong decision), or of another kind.

\subsection{Technical-Tactical Observational Tool Validation and Preliminary Results}

Regarding the results of the generalisability analysis, the $\mathrm{G}$ coefficients were optimal (Table 6). The first model $(\mathrm{CB} / \mathrm{O})$ showed a $\mathrm{G}$ coefficient equal to one $(\mathrm{G}=0.998)$, reflecting the high reliability of the observers. In the second design $(\mathrm{O} / \mathrm{C})$, the $\mathrm{G}$ coefficient was 0 , showing categories that reflect the different combat situations and categories that are E/ME in the frequency with which they appear. The third model $(\mathrm{C} / \mathrm{B})$ showed $\mathrm{G}$ coefficients tending to one ( 0.56$)$ but remaining below the recommended values $(G>0.80)$. D-study (Table 6 ) revealed a $\mathrm{G}$ coefficient $=0.83$ when 20 bouts were analysed ( 5 per tournament), supporting the extrapolation of the results to the population of interest. Additionally, the results of ICC (ICC = 0.99), Kendall's Tau-b (ranging from 0.94 to 0.96), and Cohen's kappa (ranging from 0.86 to 0.98 ) revealed excellent-to-perfect agreement between observers (O1 and $\mathrm{O} 2 ; \mathrm{O} 2$ and $\mathrm{O} 3 ; \mathrm{O} 1$ and $\mathrm{O} 3$ ). 
Table 6. G and D study of the models tested with $\mathrm{O}^{*} \mathrm{C}^{*} \mathrm{~B}$ multifaceted models.

\begin{tabular}{cccccccc}
\hline & G Study & \multicolumn{5}{c}{ D Study } \\
\hline $\begin{array}{c}\text { Sources of } \\
\text { Variation }\end{array}$ & $\begin{array}{c}\text { Sum of Squares } \\
\text { (Type III) }\end{array}$ & $\mathbf{d f}$ & & $\mathbf{R} 1$ & $\mathbf{R} 2$ & $\mathbf{R} 3$ & $\mathbf{R} 4$ \\
\hline$[\mathrm{o}]$ & 0.031 & 2 & {$[\mathrm{o}]$} & $(3 ;$ inf $)$ & $(3 ;$ inf $)$ & $(3 ;$ inf $)$ & $(3 ;$ inf $)$ \\
\hline$[\mathrm{c}]$ & 456.671 & 16 & {$[\mathrm{c}]$} & $(17 ;$ inf $)$ & $(17 ;$ inf $)$ & $(17 ;$ inf $)$ & $(17 ;$ inf $)$ \\
\hline$[\mathrm{o}][\mathrm{c}]$ & 2.809 & 32 & {$[\mathrm{~b}]$} & $(5 ;$ inf $)$ & $(10 ;$ inf $)$ & $(15 ;$ inf $)$ & $(20 ;$ inf $)$ \\
\hline$[\mathrm{b}]$ & 541.8 & 4 & N observ. & 255 & 510 & 765 & 1020 \\
\hline$[\mathrm{o}][\mathrm{b}]$ & 0.211 & 8 & G coeff. & 0.557 & 0.715 & 0.79 & 0.834 \\
\hline$[\mathrm{c}][\mathrm{b}]$ & 810.746 & 64 & Error & 0.849 & 0.424 & 0.283 & 0.212 \\
\hline$[\mathrm{o}][\mathrm{c}][\mathrm{b}]$ & 4.122 & 128 & SD error & 0.921 & 0.651 & 0.532 & 0.461 \\
\hline
\end{tabular}

Note. [o] indicates observers, [c] indicates categories, and [b] indicates bouts.

Preliminary results on the percentage of occurrence of the updated technical-tactical categories are included in Tables 7 and 8. As shown in Figure 8, offensive actions predominate $(71.46 \%)$, followed by actions with competitors on standby $(58.38 \%)$, while defensive actions account for only $25.16 \%$ of those registered.

Table 7. Percentages of occurrence (\%) of the different categorical actions of the updated observational tool.

\begin{tabular}{cccccccccc}
\hline & Offensive & Defensive & Both & Proper & Adversary & Standby & Attacks & $\begin{array}{c}\text { Counter } \\
\text { Attacks }\end{array}$ & Defence \\
\hline Beijing 2008 & 40.00 & 20.00 & 40.00 & 20.00 & 40.00 & 40.00 & 20.00 & 20.00 & 20.00 \\
London 2012 & 45.71 & 11.43 & 42.86 & 31.43 & 25.71 & 42.86 & 31.43 & 14.29 & 11.43 \\
GP Manchester 2014 & 70.59 & 11.76 & 17.65 & & 29.41 & 17.65 & 52.94 & 17.65 & 11.76 \\
Rio de Janeiro 2016 & 42.27 & 18.56 & 39.18 & 34.02 & 26.80 & 39.18 & 34.02 & 8.25 & 18.56 \\
\hline
\end{tabular}

Table 8. Percentages of occurrence (\%) of the different technical-tactical actions of the updated observational tool.

\begin{tabular}{ccccccccc}
\hline & Simple & Comb. & Correct. & Direct. & Indirect. & Anticipat. & Simult. & Subseq. \\
\hline Beijing 2008 & 20.00 & 0.00 & 0.00 & 0.00 & 0.00 & 0.00 & 0.00 & 20.00 \\
London 2012 & 8.57 & 0.00 & 0.00 & 14.29 & 8.57 & 11.43 & 2.86 & 0.00 \\
GP Manchester 2014 & 41.18 & 0.00 & 11.76 & 0.00 & 0.00 & 5.88 & 11.76 & 0.00 \\
Rio de Janeiro 2016 & 9.28 & 11.34 & 2.06 & 4.12 & 7.22 & 5.15 & 3.09 & 0.00 \\
\hline & Cut & Clash & Block & Displac. & Feint & Posit. & Change & Advance Closing \\
Spaces \\
Beijing 2008 & 0.00 & 0.00 & 0.00 & 20.00 & 0.00 & 0.00 & 20.00 & 20.00 \\
London 2012 & 11.43 & 0.00 & 0.00 & 0.00 & 2.86 & 8.57 & 28.57 & 2.86 \\
GP Manchester 2014 & 5.88 & 0.00 & 0.00 & 5.88 & 0.00 & 0.00 & 11.76 & 5.88 \\
Rio de Janeiro 2016 & 4.12 & 4.12 & 4.12 & 6.19 & 5.15 & 2.06 & 21.65 & 10.31 \\
\hline
\end{tabular}

Additionally, the results showed during final combat analysed in Beijing 2008, the most effective one-point action was a subsequent counterattack, while in London 2012, one-point actions were scored with direct and indirect annulation ( $n=5$ and 1, respectively), anticipatory counterattack $(n=4)$ and simultaneous counterattack $(n=1)$. Additionally, twoand three-point actions were scored with an indirect annulation. In the GP Manchester 2014, one-point action was scored by using attacking actions (simple, $n=3$; corrected: $n=1)$, simultaneous counterattack $(n=1)$, and cut $(n=1)$. In this GP, the only three-point action was scored with a simple attack. In Rio de Janeiro 2016, one-point action was scored with simple attacks $(n=2)$, direct and indirect annulations ( $n=2$ and 4 , respectively), anticipatory counterattack $(n=2)$, and advance $(n=2)$, while two-point actions were scored with combined attacks $(n=2)$. Finally, three-point actions were scored by using attacks 
(simple, $n=2$; combined, $n=2)$, indirect annulation $(n=2)$, simultaneous counterattack $(n=2)$, and advance $(n=2)$.

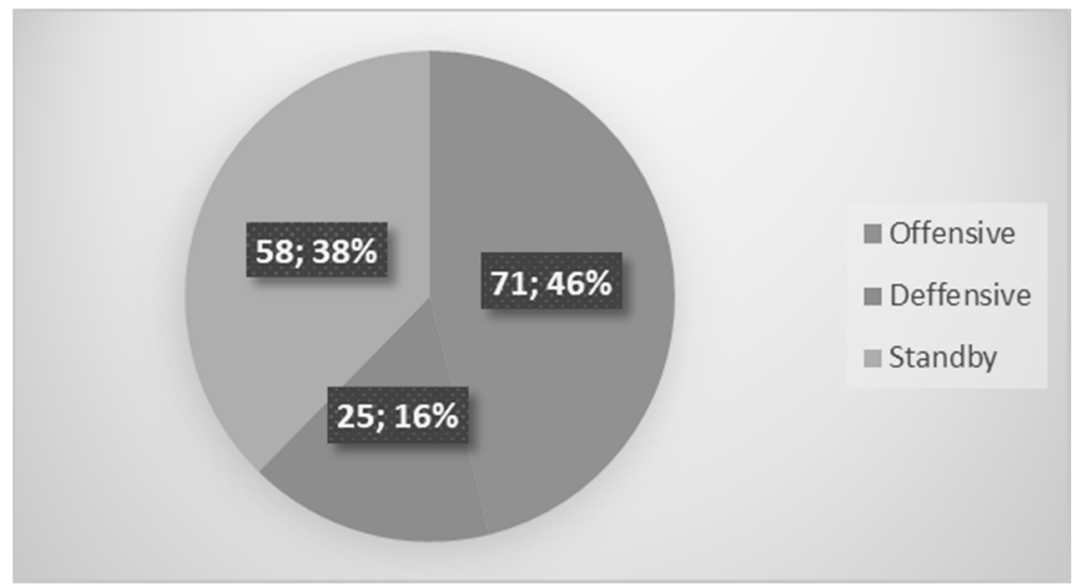

Figure 8. Percentages of occurrence of different actions either in offensive, defensive, or on-standby situations.

\section{Discussion}

The aim of the present study was to propose an updated technical-tactical categorisation for observation analysis of elite taekwondo athletes, centred in combat situations, and to validate and test its reliability in five bouts of four different elite tournaments (i.e., Olympic Games of Beijing 2008, GP Manchester 2014, Olympic Games of London 2012 and Rio de Janeiro 2016). This study represents the first attempt to synthesise the technical-tactical schema for different taekwondo tournaments. To the best of the authors' knowledge, there is no study in the taekwondo field that presents observational tools available to be used in different tournaments.

Combats sports are characterised by displaying a great variety of specific motor skills according to each 'playing situation', even though they may share a series of common variables [2]. Sampedro includes as common elements the existence of 'a 1:1 confrontation manifested through individual tactics; the importance of perceptual elements and of precision in technical-tactical execution, tailored to the opponent, normally using automatised techniques; action in close, medium and distant invasion spaces, which in the case of taekwondo are minimal and medium (1-3 m); scoring interaction with a time limit; playing action with temporal decisions adapted to the opponent and a socio-motor action space' [11].

Most studies on competition taekwondo select a series of technical or tactical actions and conduct an analysis of their occurrence or frequency during the contest [17-19], adding, in some cases, their relationship with the result obtained. However, as previous authors put it, 'once the contest begins, it all comes down to tactics' [20], and it is, therefore, necessary to establish an up-to-date categorisation of the tactical actions that arise during the contest.

Although it has been stated that points were awarded subjectively at the judges' discretion up to the Athens Olympic Games in 2004 [21], the 2008 Beijing Olympics were actually the last at which the judges assigned points, by pushing a button, according to their subjective perception. The change from a subjective scoring system to an objective system, determined by electronic devices, has given rise to research on the functioning of these devices and the implications of their use in contests [14-16,22-24] and on the influence of new technologies on the actions of taekwondo competitors, who, as a result of the application of these technologies, are thought to have changed their technicaltactical behaviour $[14,25,26]$. Given the quantity and importance of the technological and regulatory changes this sport has undergone in the past decade $[14,25,27]$ and the shortage of up-to-date scientific literature with a global perspective [20], it is desirable to define 
and organise the actions that form part of the current competitive structure of taekwondo, which has been affected by these changes.

It has been established that the execution time of taekwondo techniques is less than a second [28], and therefore, the responses to them have to be invoked, selected, and sometimes executed within this short period of time. This time pressure gives rise to an intuitive cognitive decision-making model since taekwondo athletes do not have time to consider and analyse each situation before making a decision (necessary parameters in the analytical model $[22,29,30])$, and the temporal constriction and high speed of the actions make it very difficult for them to redirect and control tactical errors on the spot [20]. It is argued that athletes who are expert decision makers are more skilled at recognising and selecting the most relevant cues from their surroundings based on perceiving 'chunks' or units of information; they have a greater repertoire of possible hypotheses and possible actions stored in their memory and are better able to calibrate their decisions by assessing uncertainties and risks [31]. These factors justify the choice of Olympic competitors, selected by World or European qualifying events and ranking tournaments, for the analysis of the competitive model, since this guarantees their mastery in this sport.

A taekwondo contest can be seen as a two-person zero-sum game; that is, a game in which one player's gains are the other's losses [4]. Taekwondo competitors will have to make decisions throughout the whole contest by searching their repertoire of possible actions for those that will enable them to solve each problem or exploit each opportunity, turning the relationship of confrontation momentarily or permanently to their advantage, so that the winner will not be the one capable of reproducing a stereotyped technical model but the one that proves to be more adapted in decision making, combined with effective and efficient technical execution, hence the importance of tactical parameters.

In taekwondo competition, a wide variety of technical actions can be observed (strikes, movements, defensive actions), and each of them can be combined with others at any moment in the contest, generating an infinite number of observable actions which have been included in various studies [27,32]. However, despite this enormous variability, a technique has no inherent purpose in itself. It is simply the best way of executing a movement, a psychomotor process devoid of intention, and it, therefore, has no meaning within the contest unless it is associated with a tactical objective. Tactical objectives invest the motor actions performed during a match with meaning, and for this reason, both competitors strive to interpret the 'semio-motor' meaning of their opponent's movements, that is, their intentions and how they aim to achieve them, determined by the contextual circumstances and the role they adopt.

Technical action is decisive when we are referring to sports in which there are no tactical problems of direct opposition, whereas in those where such problems do arise, it is more appropriate to speak of 'technical-tactical actions' [33]. Matveyev already suggested that technique is practically inseparable from tactics, capturing this idea in the concept of technical-tactical actions [2]. According to the role they adopt at each point in the contest, contestants select the technical actions associated with tactical objectives-that is, the 'technical-tactical' actions or resources-that make it possible to fulfil their objectives in each situation. It is therefore relevant to categorise these actions before conducting any subsequent observational study.

From the perspective of observational methodology, the sporting context is defined in terms of space, time, and situation, taking this to refer to the people present and the type of activity they are engaged in [34]. Thus, previous authors have stated that essential parameters for systematising the structure of combat actions in taekwondo are initiative, as well as those related to the position in space and to time [33]. Further development of this idea can be found in De la Fuente et al. [12], who identified significant tactical elements such as control of spaces, use of timing (or coordination in the execution of actions), management of pressure on the opponent (putting them under pressure to make them commit errors), and variability and correct choice between offensive, defensive, and counterattacking styles, in other words, parameters related to objectives, roles, and 
initiative [20]. Although a previous work stated that initiative only determines the roles of attacker and counterattacker in offensive actions [9], we consider that it makes it possible to distinguish the role of the attacker from the other two possible roles, counterattacker and defender, both of which are responses to the opponent's initiative.

With regard to spatial parameters, the interaction space-that is, the space which the athletes occupy during the bout-is minimal or medium, from 1 to $3 \mathrm{~m}$ [35]. The distance at which taekwondo strikes are made and how it affects the speed or force of impact have also been studied $[13,21]$. Some studies have also suggested that the space on the mat that the contestants use during interaction is an important element for analysing the contest $[21,36]$, but it has not been possible to prove that this parameter is significant in relation to gaining a technical-tactical advantage [20]. We identified variations in the interaction distance that had not been included in the reviewed literature, establishing four distinct distances: critical, supra-critical, infra-critical, and clinch or hand to hand, which constitute parameters involved in the choice of different technical-tactical resources available either in attack, counterattack, or defence role.

The studies reviewed have defined time-related subtypes of counterattack, such as anticipatory, or 'first phase', simultaneous, or 'second phase', and subsequent, or 'third phase', also known as 'descending' or 'falling' [28], but the spatial parameter, or distance between the two contestants, will also need to be incorporated with the temporal parameter: anticipatory or simultaneous counterattacks occur within the critical distance or on the verge of it, whereas 'descending' counterattacks usually begin with a dodge which initially increases the distance between the contestants and which may or may not include a change of stance or position relative to the opponent. Simultaneous counterattacks are executed by selecting techniques with an alternative trajectory, height, or impact zone to those of the attack so as to avoid clashes and increase their effectiveness.

Additionally, in relation to time, Cardinali states that in an optimum state of attention there are more than 200 milliseconds (ms) of latency between a sensory stimulus and the motor response triggered by it and that this time is longest for visual stimuli [37]. Applying this threshold is useful for discriminating between combat actions that happen to coincide and those involving a stimulus-response (or attack-counterattack) situation arising from a prior triggering action (whether it be a feint, an entry into the critical distance, an attack, or any other stimulus).

Various studies have reported the number of actions performed by each athlete during a contest, with disparate data ranging from an average of 27 actions [38], up to 31.52 and 34.72 for men and women, and even as many as 45, depending on the level of the athletes [30]. Previous studies reported discrepancies in the most effective actions during competition $[18,39]$ being the most effective attacks while posteriorly predominated counterattacks. This tendency was also shown in different studies [40] reporting different options selected by taekwondoists to score. In line with the aforementioned works, different tendencies were found to score in the four tournaments analysed. As they approach the end of the contest, athletes make more attacks, owing to the reduction in the time available $[9,10,31]$, and this is related to the 'decisive moment', the moment from which one of the two opponents dominates the match uninterruptedly until the end. On this parameter, which seems relevant, we only found studies on karate contests [41].

Further time-related issues that have been established in various studies are the duration of interactions, or fighting time, which has been determined as between 1.5 and $3 \mathrm{~s}[42,43]$, and the fighting/non-fighting (or effort/pause) ratio, which ranges between 1:2 and 1:3 [42], 1:4 [43], and 1:6 [44], and determines the effort during a taekwondo contest in functional or physiological terms; however, it has not been determined whether the changes in fighting/non-fighting ratio depend on the round of the competition or the type of technical-tactical resource used. With regard to 'non-fighting' time, the literature has tended to regard it as an unintentional pause of little tactical significance. However, the role of the athlete on standby does not correspond to a neutral or resting position; it does not lack tactical purpose and is frequently an interval in which the tension between 
the contestants reaches peak levels. The length of non-fighting time or pause between actions has been reported by a number of authors, with durations ranging from 3 to $6 \mathrm{~s}$, increasing to $8 \mathrm{~s}$ in the Olympics [21,42,43]. This increase in the non-fighting period has been attributed to greater tactical awareness and considered behaviour among athletes at international level [21], which is congruent with assigning tactical objectives to the role of the athlete on standby: by using spatial or temporal pressure or feinting-through gestemes or changes in body weight-the athlete can pursue offensive objectives that will be accomplished with a subsequent attack or counterattack, or try to avoid an attack or a warning for passivity, which would correspond to a defensive objective. The action duration's analysis has not been contemplated but future research could consider the possibility of using an observation software such as Hoisan or Lince and quantify the time of each action, allowing to establish parameters of effort:pause and thus be able to make practical proposals based on these physiological parameters.

The combat situation is a concept that has not been included or cited up till now in the theoretical or scientific literature. However, analysing it could help clarify the decisional model of taekwondo contests beyond gathering, quantifying, or serialising isolated technical or tactical elements. As a step towards this concept, the sequence of events associated with an initial action has already been observed using lag studies $[5,7,15,29,30,45,46]$. However, these studies have not aimed so far as to establish the concept of the combat situation. Close analysis of this concept can confirm the suitability/effectiveness, or unsuitability/ineffectiveness, of the technical-tactical resources selected by each contestant according to the tactical objectives, initiative, role being performed, and adaptation to the contextual or environmental conditions of the contest or situations created by the influence of the scoreline, time, and space [47]. Furthermore, and according to the second aim of this manuscript, generalisability theory, which allows researchers to ensure the reliability of the observational tools presented and to identify the sources of variability (e.g., observers, observational categories, combats/participants) that affect the process of measuring these actions [11]. The results showed optimal G coefficients and provided us with objective, valid, and reliable information on the analysed bout situations.

\section{Conclusions}

Before conducting studies on taekwondo competition based on an observational methodology, it is crucial to begin by systematically establishing categories tailored to the current circumstances of the sport and the regulatory and technological changes it has undergone. The competitive model determines whether the tasks observed in the competition are open or externally regulated, and it is, therefore, more interesting to analyse the technical-tactical actions that occur in the contest rather than stereotyped techniques.

Since the contestants are subjected to enormous time pressure during the match, the intuitive model plays the predominant part in decision making. It is, therefore, important to automatise technical-tactical actions and store up effective resources for each combat situation during training sessions. For this reason, recording and analysing the technicaltactical resources associated with each combat situation and determining whether or not they are suitable according to the tactical objectives, initiative, role, and contextual conditions of the contest are of great importance for the performance model and the optimisation of the training processes.

The criteria, categories, and resources used in taekwondo competitions, established with the advice of recognised experts, will allow the systematic, reliable, and sustainbable study over time of the factors that decisively influence decision making during combat. These parameters should be included in the methodological research on taekwondo competition as well as in the design of training tasks to improve athletes' performance. 
Author Contributions: Conceptualisation, M.B., J.J.F.-R., and R.A.-L.; data curation: M.B.; methodology, M.A.S.-G. and C.M-R.; validation, J.J.F.-R., C.M., and R.A.-L.; formal analysis, M.A.S.-G. and C.M.; writing—original draft preparation, M.B.; writing—review and editing, M.B.; supervision, J.J.F.-R. and R.A.-L. All authors have read and agreed to the published version of the manuscript.

Funding: This research received no external funding.

Institutional Review Board Statement: Not applicable.

Informed Consent Statement: Not applicable.

Conflicts of Interest: The authors declare no conflict of interest.

\section{References}

1. Moening, U. La evolución de las técnicas de patada en taekwond. Rev. Artes Marciales Asiat. 2011, 6, 117-140. [CrossRef]

2. Matveyev, L. Fundamentals of Sports Training; Progress Publishers: Moscow, Russia, 1981.

3. Hernández Moreno, J. Fundamentos del Deporte: Análisis de las Estructuras del Juego Deportivo, 4th ed.; INDE Publicaciones: Barcelona, Spain, 1994.

4. Parlebas, P. Léxico de Praxiología Motriz; Paidotribo: Badalona, Spain, 2001.

5. Menescardi, C.; Ruiz Sanchis, L.; Estevan, I.; Falco, C. Uma atualização da lógica interna de competição do combate no taekwondo. Movimento 2020, 26, e26038. [CrossRef]

6. Azuma, R.; Daily, M.; Furmanski, C. A Review of Time Critical Decision Making Models and Human Cognitive Processes. IEEEAC Paper \#1650. 2005. Available online: http:/ / www.cs.unc.edu/ \{\}azuma/aerospace06_final.pdf (accessed on 25 November 2020).

7. Benito Díez, J. and Barrientos Varela, M. Taekwondo: Técnica, Táctica, Estrategia, Competición; Paidotribo: Badalona, Spain, 2020.

8. World Taekwondo Federation. Competition Rules \& Interpretation. 2019. Available online: http://www.worldtaekwondo.org/ wp-content/uploads/2019/08/WT-Competition-Rules-Interpretation-Manchester-May-15-2019.pdf (accessed on 25 November 2020).

9. Ruiz-Sanchís, L.; Ros-Ros, C.; Bastida-Torróntegui, A.I. Esgrima en silla de ruedas, propuesta para su inclusión en el contexto escolar/Wheelchair fencing, proposal for its inclusion in the school context. Ágora para la Educación Física y el Deporte 2016, 18, 61-76.

10. Ortega-Toro, E.; García-Angulo, A.; Giménez-Egido, J.M.; García-Angulo, F.J.; Palao, J.M. Design, validation, and reliability of an observation instrument for technical and tactical actions of the offense phase in soccer. Front. Psychol. 2019, 24, 22. [CrossRef] [PubMed]

11. Menescardi, C.; Falco, C.; Hernández-Mendo, A.; Morales-Sánchez, V. Design, validation, and testing of an observational tool for technical and tactical analysis in the taekwondo competition at the 2016 Olympic games. Physiol. Behav. 2020, $224,112980$. [CrossRef] [PubMed]

12. Hernández-Mendo, A.; Blanco-Villaseñor, A.; Pastrana, J.L.; Morales-Sánchez, V.; Ramos-Pérez, F.J. SAGT: Aplicación informática para análisis de generalizabilidad. Revista Iberoamericana de Psicología del Ejercicio y el Deporte 2016, 11, 77-89.

13. Falcó Pérez, C. Estudio Sobre Parámetros Mecánicos y Distancia de Golpeo de Bandal Chagui de Taekwondo. Ph.D. Thesis, University of València, Valencia, Spain, 2009.

14. Moenig, U.; Cho, S.; Song, H. The modifications of protective gear, rules and regulations during taekwondo's evolution-From its obscure origins to the Olympics. Int. J. Hist. Sport 2012, 29, 1363-1381. [CrossRef]

15. Menescardi, C.; Falcó, C.; Hernández-Mendo, A.; Morales-Sánchez, V. Analysis of different key behavioral patterns to score in elite Taekwondoists according to the weight category and gender. Front. Psychol. 2021, 12, 713869. [CrossRef]

16. Ramazanoglu, N. Transmission of impact through the electronic body protector in taekwondo. Int. J. Appl. Sci. Technol. 2013, 3, $1-7$.

17. Falco, C.; Landeo, R.; Menescardi, C.; Bermejo, J.L.; Estevan, I. Match analysis in a university taekwondo championship. Adv. Phys. Ed. 2012, 2, 28-31. [CrossRef]

18. Kazemi, M.; Waalen, J.; Morgan, C.; White, A.R. A profile of olympic Taekwondo competitors. J. Sports Sci. Med. $2006,5,114$.

19. De la Fuente García, A.; Castejón Oliva, F.J. Análisis del combate en taekwondo:categorías para la evaluación de las acciones tácticas; estudio preliminar/An evaluation of categories for tactical actions: A preliminary study of combat analysis in Taekwondo. Cult. Cienc. Deporte 2016, 11, 157-170. [CrossRef]

20. Oliva Seba, A.; Torres Baena, F.T.; Navarro Mouchet, J. Combate Supremo; Club Karate Musoken: Tarragona, Spain, 2002.

21. Menescardi Royuela, C.; Moya-Mata, I.; Ros Ros, C.; Estevan, I. Análisis del tiempo de lucha y no lucha en taekwondistas cadetes/Fighting and non-fighting time-motion in Taekwondo cadet athletes. Sportis 2016, 2, 164-176. [CrossRef]

22. Del Vecchio, F.B.; Franchini, E.; Del Vecchio, A.H.M.; Pieter, W. Energy absorbed by electronic body protectors from kicks in a taekwondo competition. Biol. Sport 2011, 28, 75-78. [CrossRef]

23. Ramazanoglu, N. Effectiveness of protective foot and forearm guards in Taekwondo. Arch. Budo 2012, 8, 207-211. [CrossRef]

24. Leveaux, R. 2012 Olympic Games Decision Making Technologies for Taekwondo Competition. Commun. IBIMA 2020, $2012,1$. [CrossRef] 
25. Kruszewski, A.; Kúzmicki, S.; Podchul, A.; Kruszewski, M. Effect of changes in the sports regulations on the fight of Taekwondo female players on the example of Beijing Olympic Tournaments 2008 and London 2012. J. Combat. Sports Martial Arts 2014, 5, 97-100. [CrossRef]

26. Moenig, U. Martial arts versus martial sports. In Proceedings of the 1st International Conference for World Martial Arts Masterships, Chungju, Korea, 25 August 2015.

27. Pyciarz, T. Analysis of sport fight structure in Taekwondo during the Olympics in Beijing in 2008 and Senior World Championships in 2009 in terms of technical skills after regulation amendments and implementation of the electronic system of score recording. J. Combat. Sports Martial Arts 2011, 2, 109-115. [CrossRef]

28. Estevan, I.; Álvarez, O.; Falco, C.; Molina-García, J.; Castillo, I. Impact force and time analysis influenced by execution distance in a roundhouse kick to the head in Taekwondo. J. Strength Cond. Res. 2011, 25, 2851-2856. [CrossRef]

29. Menescardi, C.; Falco, C.; Estevan, I.; Ros, C.; Morales-Sánchez, V.; Hernández-Mendo, A. Is it possible to predict an athlete's behavior? The use of polar coordinates to identify key patterns in Taekwondo. Front. Psychol. 2019, 10, 1232. [CrossRef]

30. Menescardi, C.; Falco, C.; Ros, C.; Morales-Sánchez, V.; Hernández-Mendo, A. Development of a Taekwondo combat model based on Markov analysis. Front. Psychol. 2019, 10, 2188. [CrossRef]

31. Williams, A.M.; Davids, K.; Williams, J.G. Visual Perception and Action in Sport; E \& F.N.Spon: London, UK, 1999.

32. Kruszewski, A.; Jagiełło, W.; Pytel, W. The Effectiveness of Used Techniques in a Taekwondo Fight in the Olympic Tournament in Sydney 2000 and Athens 2004. Wellness and Prosperity in Different Phases of Life; Olchowik, G., Ed.; Wydawnictwo NeuroCentrum: Lublin, Poland, 2009; pp. 197-211.

33. Mirallas Sariola, J.A. El Movimiento Deportivo: Teoría General; Ergon: Barcelona, Spain, 2007.

34. Anguera Argilaga, M.T.; Blanco Villaseñor, A.; Losada, J.L. Diseños observacionales, cuestión clave en el proceso de la metodología observacional. Metodol. Cienc. Comport. 2001, 3, 135-160.

35. Sampedro, J. La inteligencia motriz deportiva:el pensamiento táctico y el proceso de entrenamiento. Gac. Gymnos 2000, 5, 4-8.

36. González de Prado, C.; Iglesias y Reig, X.; Miralles Sariola, J.A.; Esparza Pérez, G. Sistematización de la acción táctica en el Taekwondo de alta competición/Systematization of tactical action in high-level competition Taekwondo. Apunts Educación Física y Deportes 2011, 103, 56-67.

37. Cardinali, D.P. Neurociencia Aplicada: Sus Fundamentos; Editorial Médica Panamericana: Buenos Aires, Argentina, 2007.

38. Matsushigue, K.A.; Hartmann, K.; Franchini, E. Taekwondo: Physiological responses and match analysis. J. Strength Cond. Res. 2009, 23, 1112-1117. [CrossRef]

39. Kazemi, M.; Perri, G.; Soave, D. A profile of 2008 olympic Taekwondo competitors. J. Can. Chiropr. Assoc. $2010,54,243$.

40. Menescardi, C.; Estevan, I.; Ros, C.; Hernández-Mendo, A.; Falco, C. Bivariate analysis of Taekwondo actions: The effectiveness of techniques and tactics in an olympic Taekwondo championship. J. Hum. Sport Exerc. 2021, 16, 199-211. [CrossRef]

41. Tabben, M.; Miarka, B.; Chamari, K.; Beneke, R. Decisivemoment: A metric to determine success in elite karate bouts. Int. J. Sports Physiol. Perform. 2018, 13, 1000-1004. [CrossRef] [PubMed]

42. Tornello, F.; Capranica, L.; Chiodo, S.; Minganti, C.; Tessitore, A. Time motion analysis of youth olympic Taekwondo combats. J. Strength Cond. Res. 2013, 27, 223-228. [CrossRef] [PubMed]

43. Santos, V.G.; Franchini, E.; Lima-Silva, A.E. Relationship between attack and skipping in Taekwondo contests. J. Strength Cond. Res. 2011, 25, 1743-1751. [CrossRef] [PubMed]

44. Bridge, C.A.; Jones, M.A.; Drust, B. The activity profile in international Taekwondo competition is modulated by weight category. Int. J. Sports Physiol. Perform. 2011, 6, 344-357. [CrossRef] [PubMed]

45. López-López, J.A.; Menescardi, C.; Estevan, I.; Falcó, C.; Hernández-Mendo, A. Análisis técnico-táctico en Taekwondo con coordenadas polares a través del software HOISAN/Technical-tactical analysis in Taekwondo with polar coordinates through software HOISAN. Cuad. Psicol. Deport. 2015, 15, 131-142. [CrossRef]

46. Casolino, E.; Lupo, C.; Cortis, C.; Chiodo, S.; Minganti, C.; Capranica, L.; Tessitore, A. Technical and tactical analysis of youth Taekwondo performance. J. Strength Cond. Res. 2012, 26, 1489-1495. [CrossRef] [PubMed]

47. Iglesias, X.; Gasset, A.; González, C.; Anguera, M.T. Interacción competitiva y presión ambiental en deportes de combate: Aplicación de la metodología observacional. Rev. Iberoam. Psicol. Ejerc. Deporte 2010, 5, 267-282. 